\title{
THE RESEARCH ON ATMOSPHERIC PRESSURE WATER VAPOUR PLASMA GENERATION AND APPLICATION FOR THE DESTRUCTION OF WASTES
}

\author{
ViktoriJa Grigaitiene*, Andrius Tamošiūnas, Pranas Valatkevičıus \\ Plasma Processing Laboratory, Lithuanian Energy Institute, Breslaujos str. 3, LT-44403 Kaunas, Lithuania. \\ Tel. +37037401898, Fax: +370 37351271 \\ * corresponding author: vika@mail.lei.lt
}

\begin{abstract}
In the Lithuanian Energy Institute an experimental atmospheric pressure Ar/water vapour plasma torch has been designed and tested. The power of plasma torch was estimated $40 \div 69 \mathrm{~kW}$, the mean temperature of plasma jet at the exhaust nozzle was $2300 \div 2900 \mathrm{~K}$. The chemical composition of water vapour plasma was established from the emission spectrum lines at $300 \div 800 \mathrm{~nm}$ range. The main species observed in Ar/water vapour plasma were: $\mathrm{Ar}, \mathrm{OH}, \mathrm{H}, \mathrm{O}, \mathrm{Cu}$. The experiments on water vapour steam reforming were performed. The results confirmed that water vapour plasma has the unique properties - high enthalpy and environmentally friendly conditions. It could be employed for environmental purposes such as destruction of wastes into simple molecules or conversion to synthetic gas.
\end{abstract}

KEYWORDS: water steam plasma, dc plasma torch, optical emission spectrum, waste treatment.

\section{INTRODUCTION}

Water vapor plasma technology could be applied in some unique areas, such as a biomass conversion, neutralization and utilization of hazardous wastes because of high-temperature processing and heating in comparison to other thermal methods. The water vapour plasma torch serve as the source for a high enthalpy plasma stream, where the organic compounds in the wastes are dissociated into simple atoms. For the waste destruction and other environmental applications, reactive plasma containing $\mathrm{H}, \mathrm{OH}$ an $\mathrm{O}$ radicals is desired to support the chemical reactions [6]. Water vapour plasma is very suitable for fast chemical processes for generation of reactive $\mathrm{H}$ and $\mathrm{O}$, because the hydrocarbons can be decomposed effectively. Some authors have developed a water plasma generation devices for gasification of wastes [5, 2, 9] and gasification of organic compounds for the production of synthetic gas [8, 7]. Plasma assisted reforming is usually combined with catalysts [1]. But plasma itself could be as a catalyst, which stimulates chemical processes itself [4].

The water vapour plasma due to relatively high enthalpy, high chemical reactivity and high electron density and better control of the process, could be applied in many industrial fields, especially in waste treatment and effective production of hydrogen-rich gas. The new water vapour plasma device was designed and manufactured in the Lithuanian Energy Institute. The measurements of electrical and thermal characteristics of water vapour plasma generator (PG) and investigation of plasma jet parameters were established. The optical emission spectroscopy (OES) has been used for plasma diagnostics as non-contact method. It provides valuable information on real-time measurement about the plasma elemental composition, exited atomic and molecular states 3 . In this research, the primary results of thermal plasma reforming of hydrocarbon gas (propane), as low cost substance and as oxygen acceptor were investigated.

\section{EXPERIMENTAL SETUP}

An atmospheric pressure water vapour plasma jet was generated using the experimental plasma generator, which was projected and designed in the Lithuanian Energy Institute by staff of the Laboratory of Plasma Processing. The water vapour plasma generation system (Fig. 11 consists of the main interdependent parts: electricity supply (1-3), plasma torch with a reactor for waste injection (10), water vapour and shielding gas supply system (11-14), cooling system (15-17) and operation control and data monitoring system (4-9). A novel water vapour plasma torch consists of two electrodes: tungsten cathode and copper anode. Between the electrodes of the plasma generator, there is a neutral electrode where the overheated water steam is injected by a steam generator. The water vapour is used as plasma main forming gas and argon as shield gas, shielding cathode from the erosion.

The water vapour vortex in the electric arc of plasma torch is created, which reduces the condensation on the walls of the electrodes, prolongs their lifetime and provides a higher thermal efficiency of the torch. The chemical reactor is connected to the plasma torch and consists of three sections: i) for the injection of treated materials - in the case of this research it was hydrocarbon gas - propane $\left(\mathrm{C}_{3} \mathrm{H}_{8}\right)$, ii) the reaction chamber, where the conversion of propane occurs, iii) the outflow and analysis of the production samples. 


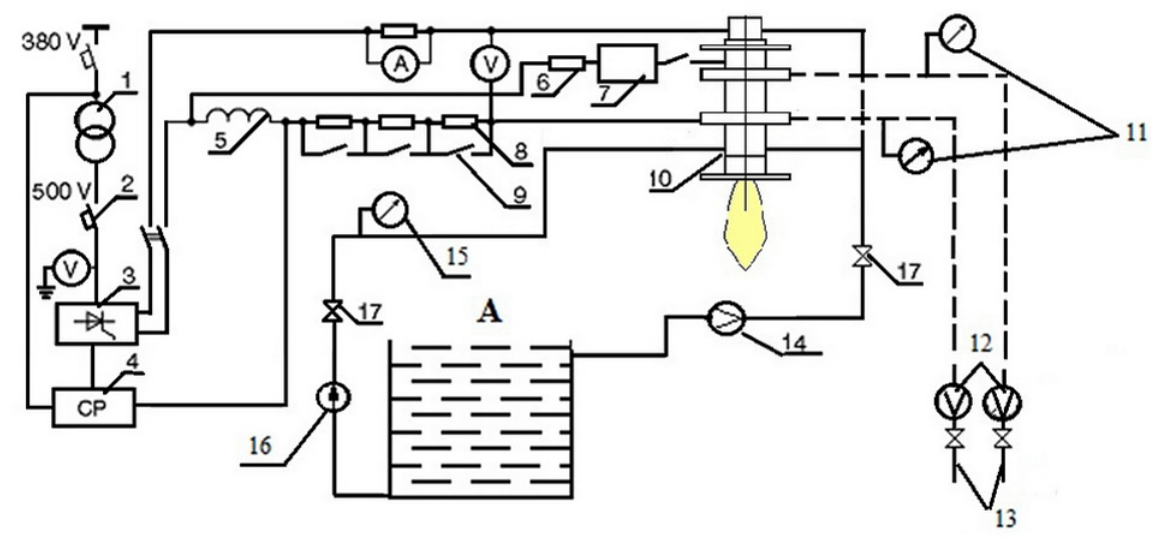

FiguRE 1. A diagram of a water vapour plasma system. 1-transformer, 2-cutout, 3- thyristors rectifier, 4-control board, 5-inductor, 6-resistor, 7-oscillator, 8-rheostat, 9-switch contactor, 10-PG, 11, 15-diaphragms, 12, 14-critical flow nozzles, 13, 17-valves, 16-water pump.

Water vapour is ionized immediately by an electric arc in the discharge chamber of the plasma torch, where it dissociates into atomic elements. The emission spectra of exhaust water vapour plasma jet at the exit nozzle of PG were measured in the spectral range of $250 \div 800 \mathrm{~nm}$ wavelength by means of AOS4-1 spectrometer. The spectral resolution was $0.05 \mathrm{~nm}$ (at $250 \mathrm{~nm}$ ) and $0.5 \mathrm{~nm}$ (at $800 \mathrm{~nm}$ ) and the focal distance was $0.05 \mathrm{~m}$. The spectrometer is controlled via a standard USB 2.0 connection. The optical fiber directs the emission from the plasma radiation into an optical interface of the multiple grating.

The primary experiments on steam plasma reforming of propane gas were performed. The reaction products were cleaned from the moisture and were collected in the special gas sampling vessels. The exploration of the by-products was carried out by a gas chromatograph (GC) (Agilent 7890A) with a dual channel and thermal conductivity detectors (TCDs). The front channel with nitrogen carrying gas $\left(10 \mathrm{ml} \mathrm{min}^{-1}\right)$ was used for separating $\mathrm{O}_{2}, \mathrm{CO}_{2}, \mathrm{CH}_{4}, \mathrm{CO}$ and light hydrocarbons. In the meanwhile, hydrogen was separated through the molecular sieve and packed column of the back channel which operated on helium carrier gas $\left(30 \mathrm{ml} \mathrm{min}^{-1}\right)$.

\section{Results AND Discussion}

Applying a plasma generator for a waste treatment application, the main operational parameters are temperature and the flow rate of the plasma jet. The operational parameters and stable work of the system are dependent on the construction of the plasma generator and its thermal and electrical parameters. The main operational characteristics of the plasma torch were established and are as follows: electric arc current $130 \div 210 \mathrm{~A}$, electric arc voltage $230 \div 330 \mathrm{~V}$, power of the plasma source $40 \div 69 \mathrm{~kW}$, water flow rate for the cooling of the torch $0.1 \times 10^{-3} \mathrm{~kg} \mathrm{~s}^{-1}$, argon (cathode shield) gas feeding $5.2 \times 10^{-4} \mathrm{~kg} \mathrm{~s}^{-1}$, water

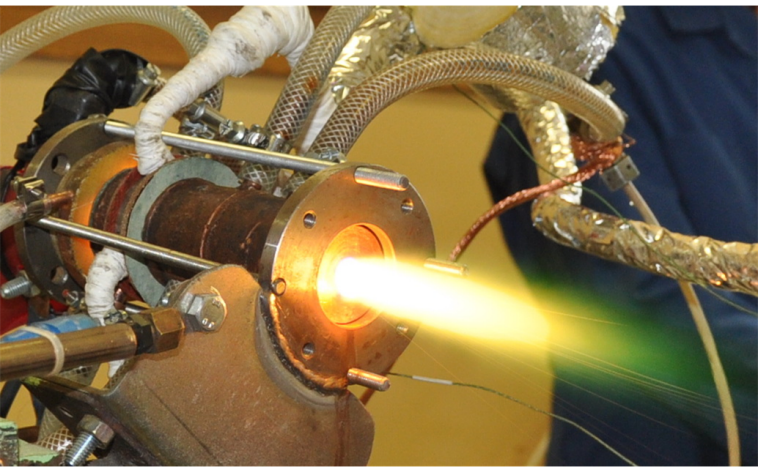

FIGURE 2. Water vapour plasma generator in operation.

vapour feeding $1.48 \div 4.48 \times 10^{-3} \mathrm{~kg} \mathrm{~s}^{-1}$, propane flow rate in decomposition process $0.34 \times 0.66 \times 10^{-3} \mathrm{~kg} \mathrm{~s}^{-1}$. Water vapour plasma torch in operation is showed in Fig. 2. The mean temperature of plasma jet $2300 \div 2900 \mathrm{~K}$, mean velocity of plasma jet at the torch outlet was $200 \div 400 \mathrm{~m} \mathrm{~s}^{-1}$ at the outlet nozzle of the torch.

The volt-ampere characteristics of the plasma torch in different operating regimes were established and presented in Fig. 3 .

The obtained results showed that the voltage of the electric arc and the power of plasma torch mainly depend on the water vapour flow rate. A part of falling curve may appear as a result of the insignificant influence of the channel walls of a plasma generator on an electric arc, i.e. a tangentially supplied water vapor flow rate has a significant influence on the thickness of the boundary layer. Thus, the diameter of an electric arc column decreases. The part of a rising curve appears when the channel walls of plasma generator influence the characteristics of the electric arc, i.e. energy quantity is transferred to the channel walls. Then the thickness of a boundary layer thins down.

The optical emission spectra were measured for the argon/water vapour plasma jet in the wavelength 


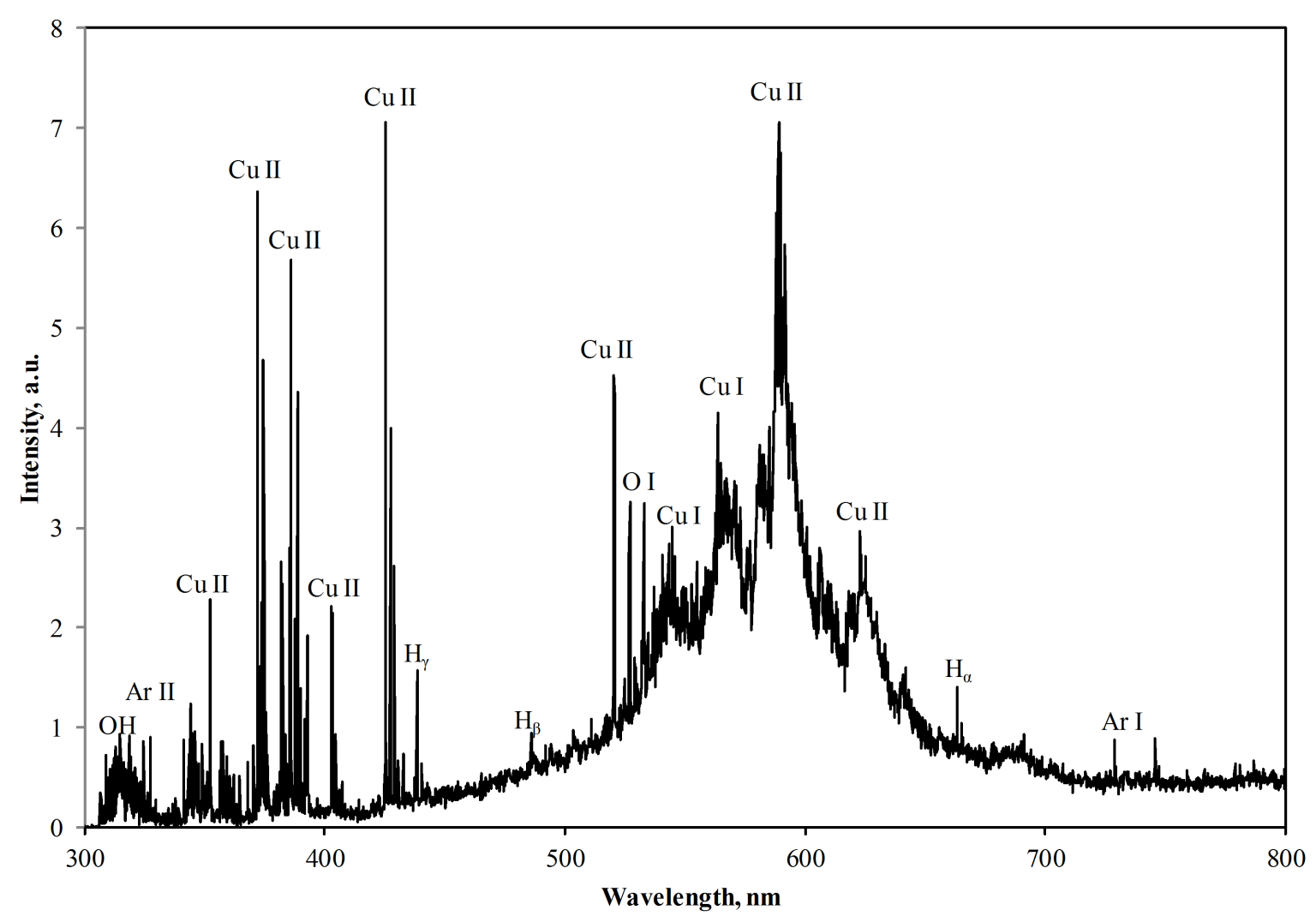

Figure 4. Optical emission spectra of Ar (as shield gas)/water vapour plasma at $P=50.6 \mathrm{~kW}$, water vapor flow rate $3.51 \times 10^{-3} \mathrm{~kg} \mathrm{~s}^{-1}$.

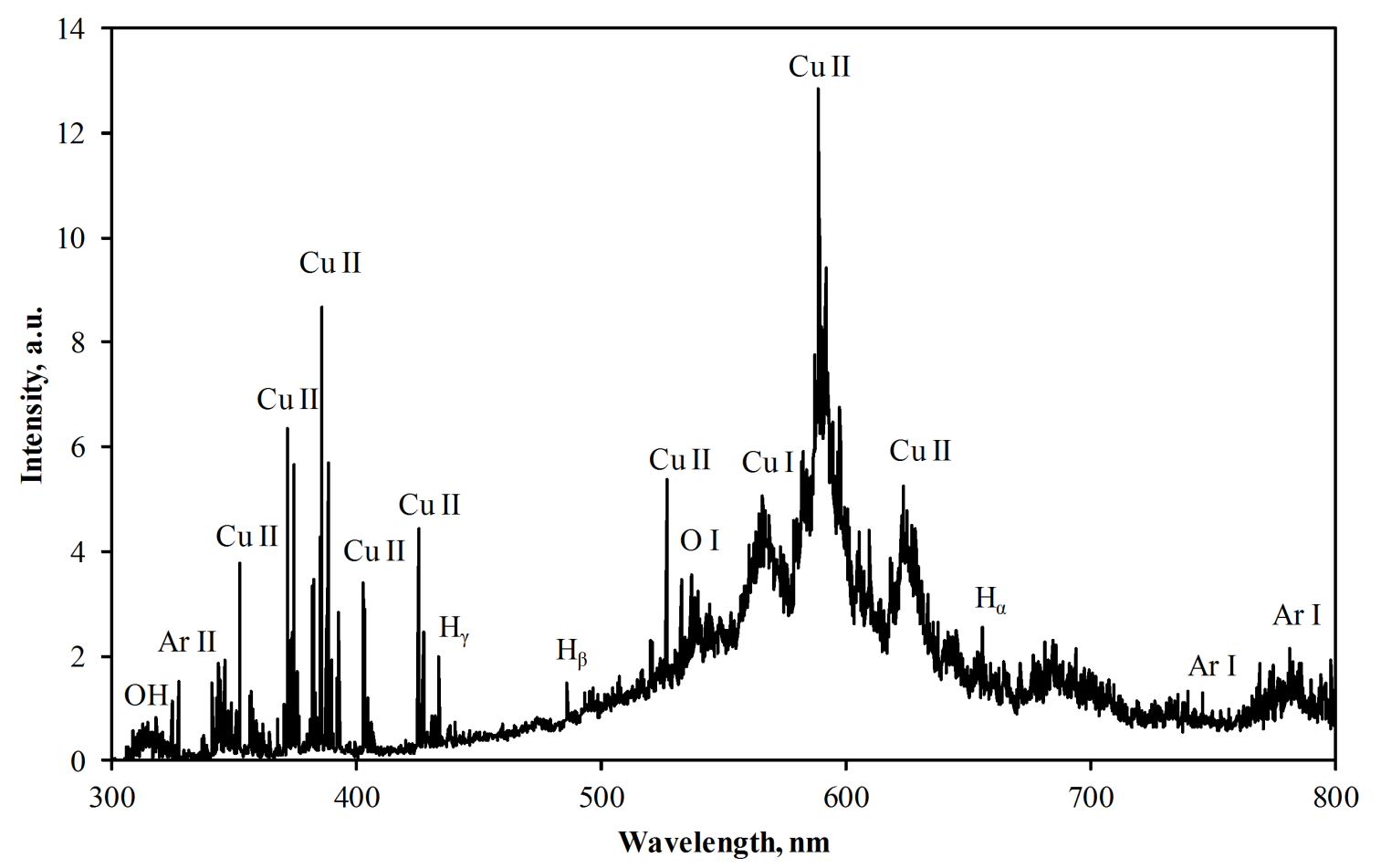

Figure 5. Optical emission spectra of Ar (as shield gas)/water vapour plasma at $P=69.1 \mathrm{~kW}$, water vapor flow rate $4.48 \times 10^{-3} \mathrm{~kg} \mathrm{~s}^{-1}$. 


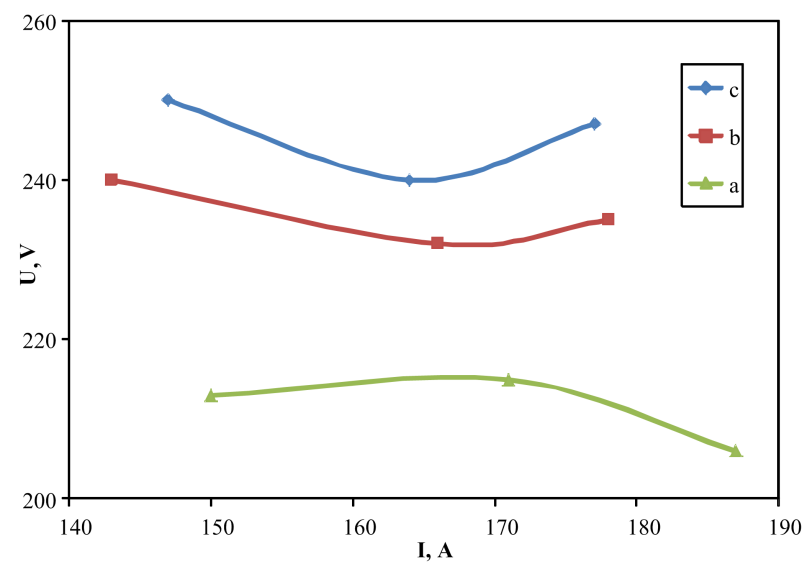

FIGURE 3. Volt-ampere characteristics of water vapor plasma torch, when the water vapor flow rate, $\times 10^{-3} \mathrm{~kg} \mathrm{~s}^{-1}$ : $\mathrm{a}-2.9 ; \mathrm{b}-3.4 ; \mathrm{c}-4.2$.

range from 300 to $800 \mathrm{~nm}$ (Figs. 4 and 5 ) at the $7 \mathrm{~mm}$ distance from the outflow nozzle of the plasma generator. The experiment conditions in the emission spectra measuring (Fig. 4) were the following: the power of plasma torch $P=50.6 \mathrm{~kW}$, the electrode of copper was used, argon flow rate $5.2 \times 10^{-4} \mathrm{~kg} \mathrm{~s}^{-1}$ and water vapour flow rate $3.51 \times 10^{-3} \mathrm{~kg} \mathrm{~s}^{-1}$. In another case (Fig. 5), the power of plasma torch $P=69.1 \mathrm{~kW}$, argon flow rate $5.2 \times 10^{-4} \mathrm{~kg} \mathrm{~s}^{-1}$ and water vapour flow rate $4.48 \times 10^{-3} \mathrm{~kg} \mathrm{~s}^{-1}$.

The main species observed in $\mathrm{Ar} /$ water vapour plasma were: $\operatorname{Ar}(\mathrm{I}), \operatorname{Ar}(\mathrm{II}) \mathrm{OH}, \mathrm{H}, \mathrm{O}(\mathrm{I}), \mathrm{Cu}(\mathrm{I}), \mathrm{Cu}(\mathrm{II})$. The emission spectra showed the peaks of hydrogen atoms: $\mathrm{H} \alpha(656.2 \mathrm{~nm}), \mathrm{H} \beta(486.1 \mathrm{~nm})$ and $\mathrm{H} \gamma$ $(434.1 \mathrm{~nm})$, which belong to Balmer series of $\mathrm{H}_{2}$. The sharp peaks of $\mathrm{Cu}(\mathrm{I})$ and $\mathrm{Cu}(\mathrm{II})$ show an intensive erosion process and evaporation of the used electrodes. High instability ratios of the plasma flow were observed. Therefore, the performed emission spectra measurements confirms that water vapour was decomposed into $\mathrm{H}, \mathrm{O}$ and $\mathrm{OH}$ radicals by a high voltage DC electric arc. The main disadvantage of the water vapour plasma torch was observed: the intensive electrode erosion due to electric arc shunting in the discharge chamber, limiting the lifetime of the equipment.

According to the results (Figs. 6 and 7), the concentrations of hydrogen always exceeded 60 percent in volume. It was observed that it slightly depended on the $\mathrm{H}_{2} \mathrm{O} / \mathrm{C}_{3} \mathrm{H}_{8}$ ratio.

The increased feeding of propane from 0.34 to $0.66 \times 10^{-3} \mathrm{~kg} \mathrm{~s}^{-1}$, when the feeding of water vapor flow rate was fixed, showed that the level of hydrogen concentration slightly increased.

The same tendency was observed when the content of water vapor from 3.51 to $4.48 \times 10^{-3} \mathrm{~kg} \mathrm{~s}^{-1}$ was increased, at a fixed propane rate. The results demonstrate, that changing $\mathrm{H}_{2} \mathrm{O} / \mathrm{C}_{3} \mathrm{H}_{8}$ ratio from 5.3 to 13.2 , the concentrations of $\mathrm{CO}$ decreased from 22.96 to 14.6 percent, while that of $\mathrm{CO}_{2}$ increased from 7.74 to 11.27 percent, respectively. This could be explained that the combination mechanism between $\mathrm{C}$ and $\mathrm{O}$

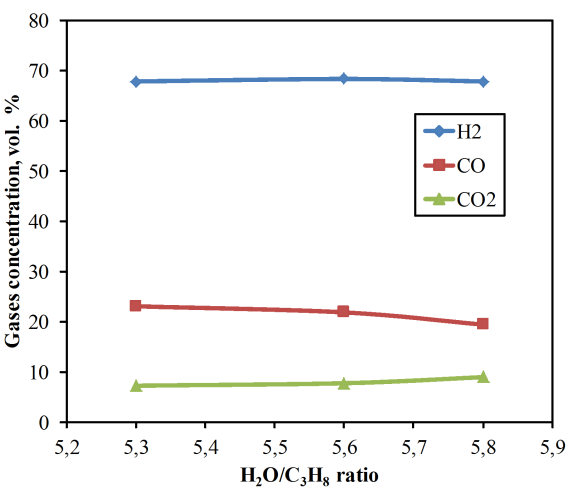

Figure 6. The composition of gases at the output of the plasma-chemical reactor (in vol percent) as a function of $\mathrm{H}_{2} \mathrm{O} / \mathrm{C}_{3} \mathrm{H}_{8}$ ratio; $\mathrm{H}_{2} \mathrm{O}$ vapour flow rate $3.51 \div 4.48 \times 10^{-3} \mathrm{~kg} \mathrm{~s}^{-1}$, propane $0.34 \times 10^{-3} \mathrm{~kg} \mathrm{~s}^{-1}$.

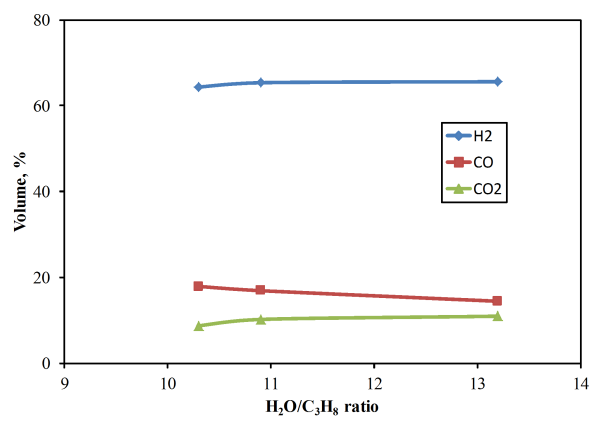

Figure 7. The composition of gases at the output of the plasma-chemical reactor (in vol percent) as a function of $\mathrm{H}_{2} \mathrm{O} / \mathrm{C}_{3} \mathrm{H}_{8}$ ratio; $\mathrm{H}_{2} \mathrm{O}$ vapour flow rate $3.51 \div 4.48 \times 10^{-3} \mathrm{~kg} \mathrm{~s}^{-1}$, propane $0.66 \times 10^{-3} \mathrm{~kg} \mathrm{~s}^{-1}$.

atoms differed and the selectivity of $\mathrm{CO}$ decreased. It implies that during the oxidation $\mathrm{O}$ atom contributed to $\mathrm{CO}+\frac{1}{2} \mathrm{O}_{2}=\mathrm{CO}_{2}$ instead of $\mathrm{C}+\mathrm{O}=\mathrm{CO}$, thus, the selectivity of $\mathrm{CO}_{2}$ increased.

\section{Conclusions}

An experimental linear DC water vapor plasma generator operating at atmospheric pressure has been designed and tested. The thermal and electrical characteristics of the water vapor plasma torch were carried out to ensure the stable work of the plasma generator. The mean plasma flow temperature at the torch outlet varied within limits of $T=2600 \div 2900 \mathrm{~K}$. The performed optical emission spectra measurements of the $\mathrm{Ar}$ /water vapour plasma jet confirmed that water vapour was decomposed into $\mathrm{H}, \mathrm{O}$ and $\mathrm{OH}$ radicals by a high voltage dc electric arc. The spectra also showed the peaks of $\mathrm{H} \alpha(656.2 \mathrm{~nm}), \mathrm{H} \beta(486.1 \mathrm{~nm})$ and $\mathrm{H} \gamma(434.1 \mathrm{~nm})$, which belong to the Balmer series describing the spectral line emissions of the hydrogen atoms. Beside these important groups, the emission spectrum contains other emission lines such as $\operatorname{Ar}(\mathrm{I})$, 
$\operatorname{Ar}(\mathrm{II}), \mathrm{Cu}(\mathrm{I}), \mathrm{Cu}(\mathrm{II})$. Copper electrode strongly evaporated.

The performed plasma reforming experiments and results showed almost 100 percent conversion of $\mathrm{C}_{3} \mathrm{H}_{8}$ gas. The concentration of hydrogen has been found always exceeding 60 percent in volume (maximum value 68 percent) in generated by-products. The high temperature and high chemical reactivity of water vapour plasma are the essential parameters for plasma reforming. The results would be useful for the design of projecting a new plasma equipment used for the decomposition of biomass and organic waste into hydrogen-rich synthetic gas.

\section{ACKNOWLEDGEMENTS}

The research work is funded by the Research Council of Lithuania, the grant No. ATE-10/2012.

\section{REFERENCES}

[1] R. F. Horng, M. P. Lai, Y. P. Chang, et al.

Plasma-assisted catalytic reforming of propane and an assessment of its applicability on vehicles. Internat $J$ of Hydrogen Energ 34(15):6280-6289, 2009.

[2] M. Hrabovsky, M. Konrad, V. Kopecky, V. Sember. Processes and properties of electric arc stabilized by water vortex. IEEE Trans Plasma Sci 25(5):833-839, 1997.
[3] C. O. Laux, T. G. Spence, C. H. Kruger, R. N. Zare. Optical diagnostics of atmospheric pressure air plasmas. Plasma Sources Sci T 12:125-138, 2003.

[4] G. Ni, Y. Lan, CH. Cheng, et al. Reforming of methane and carbon dioxide by DC water plasma at atmospheric pressure. Internat $J$ of Hydrogen Energ 36:12869-12876, 2011.

[5] Sh. Shimbara, T. Watanabe. Water plasma generation under atmospheric pressure for waste treatment. In Proceedings of Regional Symposium on Chemical Engineering, pp. C7 1-6. Makati, Philippines, 2003.

[6] M. Tendler, P. Rutberg, G. Van Oost. Plasma based waste treatment and energy production. Plasma Phys Contr F 47(5A):219-230, 2005.

[7] G. Van Oost, M. Hrabovsky, V. Kopecky, et al. Pyrolysis/gasification of biomass for synthetic fuel production using a hybrid gas-water stabilized plasma torch. Vacuum 83:209-212, 2009.

[8] T. Watanabe. Water plasma generation under atmospheric pressure for waste treatment. ASEAN J Chem Eng 5(1):30-34, 2005.

[9] M. H. Yuan, Narengerile, T. Watanabe. DC water plasma at atmospheric pressure for the treatment of aqueous phenol. Environ Sci Technol 44(12):4710-4715, 2010 . 